\title{
SEM RECEITA: CONSIDERAÇÕES SOBRE TRADIÇÃO, RUPTURA E O FREEFORM EM TRABALHOS DE AGULHA COMO DIRETRIZ DE PROCESSO NO PROJETO PÉROLA
}

Regina Barbosa ${ }^{1}$

Universidade Anhembi Morumbi

Resumo: No texto a seguir faz-se considerações sobre a prática tradicional dos trabalhos de agulha a partir do aprendizado e do exercício de seguir receitas e a possibilidade de, a partir do conhecimento dos pontos e materiais fundamentais, passar à ruptura com a forma conhecida de produzir e pensar os têxteis e o próprio Design de Moda. Toma-se o realizado pelo Moda e Resiliência Coletivo de Design de Moda (coletivo de designers de Moda formado na Universidade Anhembi Morumbi) para o Projeto Pérola a fim de ilustrar o procedimento metodológico do freeform, oriundo do rompimento com a forma tradicional.

Palavras-chave: Design; Design de Moda; Têxteis; Tradição; Ruptura

\begin{abstract}
The following paper brings considerations about the practice of traditional handcraft/needlecraft labors through learning and exercising how to read and follow recipes and the possibility of, since one knows the basic stitches and points and fundamental materials, break the known form of producing and thinking textiles and even Fashion Design itself. It is taken what is made by the Fashion and Resilience Collective of Fashion Design - Moda e Resiliência Coletivo de Design de Moda - (collective formed by Universidade Anhembi Morumbi's fashion designers) for the Projeto Pérola in order to illustrate the methodological procedure of freeform, that comes from rupturing traditional means of producing handmade textiles.
\end{abstract}

Keywords: Design; Fashion Design; Textiles; Tradition; Rupture

\footnotetext{
${ }^{1}$ Docente dos Bacharelados em Negócios e Design de Moda da Universidade Anhembi Morumbi, Bacharel em Negócios da Moda com Habilitação em Design de Moda e Mestre em Design pela Universidade Anhembi Morumbi. Ministra as disciplinas ligadas às visualidades e à expressão por meio do Desenho e demais expressões plásticas bidimensionais além de orientar projetos interdisciplinares e Trabalhos de Conclusão de Curso (TCC). Na pós- graduação, leciona Processos Criativos.
} 


\title{
1. INTRODUÇÃO
}

Com o presente artigo, deseja-se desenvolver uma discussão a respeito dos fazeres têxteis artesanais, especialmente os trabalhos de agulha, a saber: o tricô, o crochê e o bordado, o aprendizado e o desenvolvimento tradicional dos mesmos e o momento em que o possuidor do conhecimento sente-se à vontade para experimentar, rompendo com a regra e produzindo a partir de então têxteis em que se pode prescindir da fórmula, neste caso conhecida como receita.

Ao trabalho sem receita denomina-se também freeform, a forma livre, que aqui também é abordada como metodologia e questão, uma vez que romper padrões é a proposta fundamental do realizado pelo Moda e Resiliência Coletivo de Design para o Projeto Pérola, grupo e projeto sobre os quais esta autora se deterá um pouco mais adiante para maiores esclarecimentos.

\section{TRADIÇÃO E RUPTURA NOS TRABALHOS DE AGULHA}

\begin{abstract}
A única certeza que eu seguro nas mãos é a linha que costuro, que me liga umbilicalmente ao mundo. Me interessa aprimorar a ótica tátil. Olho que mergulha o mundo com o corpo todo.
\end{abstract}

Edith Derdyk - Linha de Costura

Houve um tempo em que toda mulher deveria saber algumas coisas caso quisesse entender-se como tal, socialmente. Era preciso saber cozinhar, gerenciar uma casa, tirar manchas difíceis, entreter e produzir têxteis. Para que não houvesse dúvida de como resolver tais problemas, um sem número de publicações foram produzidas, dentre elas, o livro de Vera Sterblitch "O Que Toda Dona de Casa Deve Saber" (figura1).

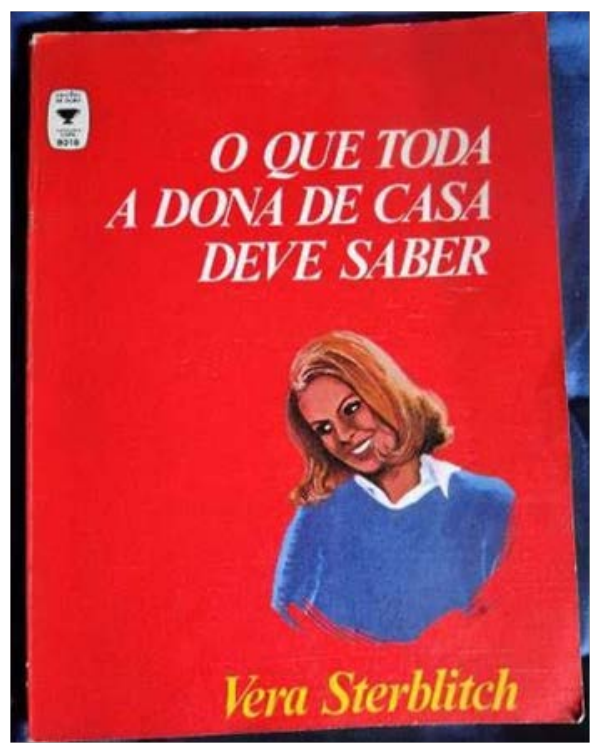

Figura 1: O Que Toda Dona de Casa Deve Saber, de Vera Sterblitch, presença constante em inúmeras gavetas femininas de meados do século $\mathrm{XX}$, manual para solução de problemas domésticos

Ou seja, se ao homem cabia o provento, à mulher cabia transformar o trazido para casa em alimento, agasalho e acolhimento. 
Estas prendas do lar eram transmitidas de geração em geração, perpetuadas na intimidade. Cabia àquela que tivesse maior experiência, colher a mão das meninas que cresciam e ensinar a técnica até a excelência, produzindo pontos idênticos um ao outro. Não se podia errar como um errante e deixar que o fazer tomasse sua própria forma. Os desvios e as incertezas eram impensáveis, pois era preciso fazer certo, da maneira tradicional, como sempre se fez. Como todas deviam saber fazer, perpetuamente.

... people have always devoted considerable time and care to working rugs, covers, hangings and other household items, in local styles. (GOSTELOW, 1983, p. 8) Havia não só a maneira correta de fazer, mas uma infinidade de publicações populares que traziam as receitas. Essas publicações existem ainda hoje e são facilmente encontradas em bancas de jornal, lojas de aviamento (vulgarmente conhecidas como "armarinhos" ou "bazares") e mais contemporaneamente, com o advento da internet e a proliferação de vídeostutoriais, em sites como YouTube.

Estas publicações, dirigidas ao público feminino, ensinam o passo a passo da realização de cada peça. As receitas, apresentadas em gráficos, apontam a quantidade e os tipos de pontos, a distribuição das cores, e são acompanhadas por legendas que mostram, numa espécie de quadro-a-quadro, como realizar cada ponto (Figuras 2 e 3 ).

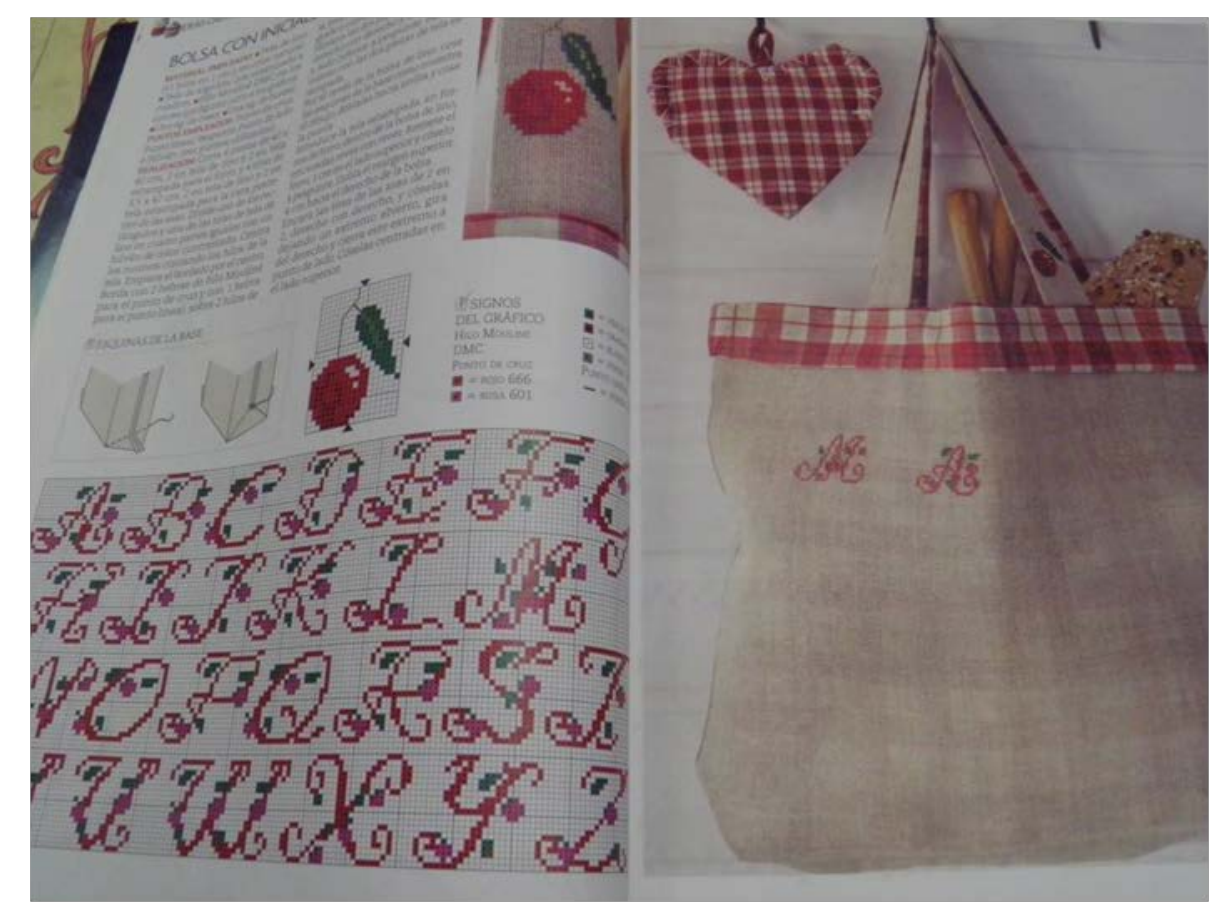

Figura 2: Revista Labores del Hogar, no 663 página 18 - Receita de bordado e confecção para bolsa em tela bordada. A descrição por escrito é acompanhada por foto e receita. 


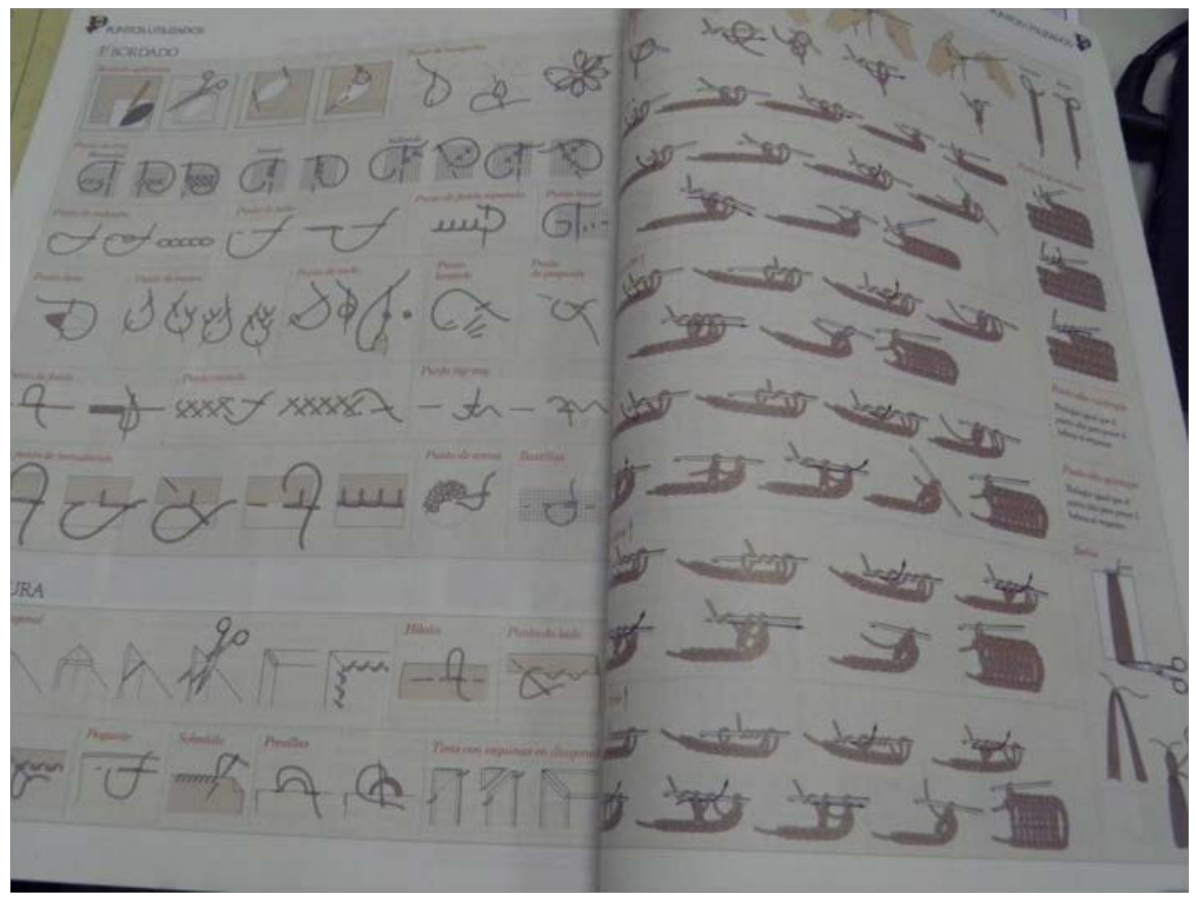

Figura 3: Revista Labores del Hogar no 663 páginas 142 e 143 - Descrição visual dos pontos de bordado, tricô, crochê e costura propostos neste número da revista.

É curioso, ao visitar tais publicações, que as mais antigas (Figuras 4, 5, 6 e 7) apenas trouxessem como receita os riscos a ser copiados e a indicação dos pontos, mas não o "como fazer". Presume-se então que aquela que adquirisse a revista já soubesse o que riscos e nomes significavam.
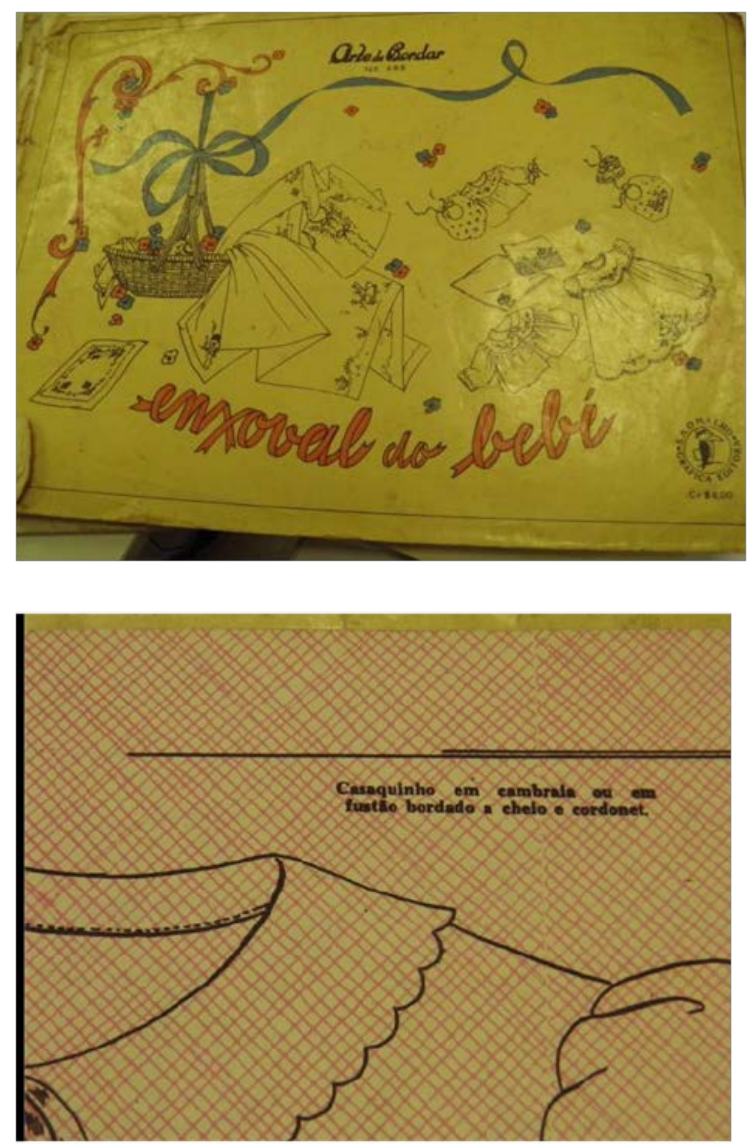

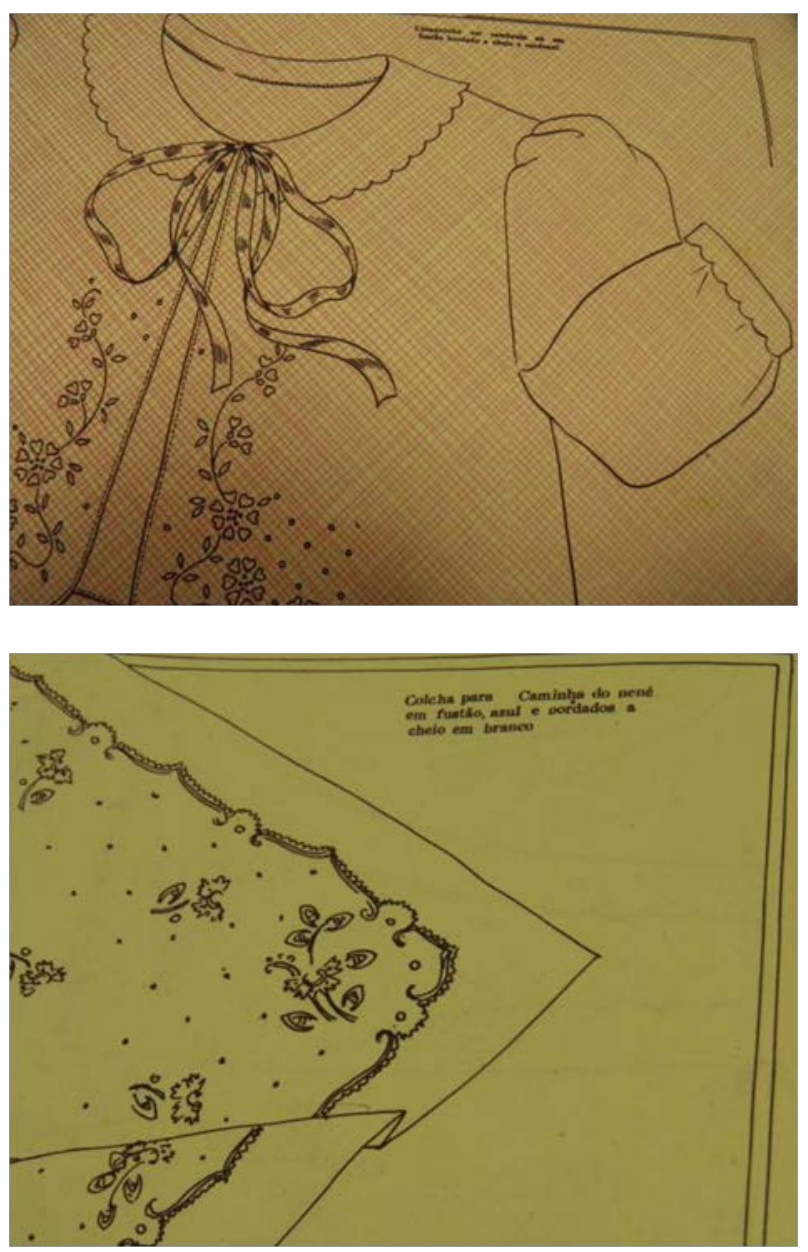

Figuras 4, 5, 6 e 7: Revista Arte de Bordar, no 489 - Junho de 1973. A ilustração da peça a ser executada é acompanhada por nomeação dos pontos. Não há, na revista, descritivo do modo de fazer cada ponto, nem por escrito, nem pordiagrama.

Diz-se que "quem conta um conto aumenta um ponto". Eis uma das muitas expressões populares que se relacionam com as práticas de crochetar, tricotar e fiar e apontam para o universo feminino, em que os encontros para produzir têxteis também proporcionam diálogos e aprendizagens sobre si e a história do grupo. Ora, se ao contar o conto, aumentar-se um ponto? O que se pode fazer?

Quem "frequentou" o aprendizado técnico tradicional e doméstico da classe média brasileira até os anos 1980, aproximadamente, sabe qual é/era a (con)seqüência: desfazer o erro e começar de novo. Seguir a receita até ficar certo, até, ao fim, a peça realizada parecer com a da fotografia da revista.

Mas, como em toda receita repetida à exaustão como na prática alquímica da cozinha, um dia o realizador passa a incorporar os seus desvios, exageros e enganos e começa a inventar, afinal, "não é aconselhável infringir as normas até que se saiba como cumpri-las"” (T.S. Elliot apud POYNOR, 2003, p.12).

Com o crochê, o tricô e o bordado, raramente se "inventa" demais com os ingredientes, mas as maneiras de combiná-los podem produzir resultados inesperados.

\footnotetext{
${ }^{2}$ No es aconsejable infringir las normas hasta que uno sepa cómo cumprirlas. (Tradução desta Autora)
} 
É esse desejo de inesperado que tem proporcionado a uma leva recente de neófitas (e neófitos) nos trabalhos de agulha a repensar a necessidade da receita para produzir suas peças.

Deixando o erro permanecer em seus projetos ou efetivamente incorporando-o a seus processos em que não existe uma fotografia de revista como modelo a alcançar, surge o conceito de freeform, ou o trabalho com forma livre de executar, finalizar e, muitas vezes, vestir.

Liberado, assim, da necessidade de correção, o designer mune-se de material e técnica de sua preferência e submerge na experiência de fazer, sem perguntas, experimentando mudanças súbitas de sentido, a inserção a qualquer momento de outra técnica e a exploração de materiais, arrancando, como diz Preciosa (2010), "da realidade não seu estoque de provisões, mas seu estojo de possíveis".

Essa é a proposição metodológica incorporada à realização do Projeto Pérola, realizado pelo Moda e Resiliência Coletivo de Design de Moda, formado por voluntários dos Bacharelados em Design de Moda e Negócios da Moda da Universidade Anhembi Morumbi, e o Centro de Referência de Saúde da Mulher Hospital Pérola Byington ${ }^{3}$. A parceria firmada com o Hospital serve ao coletivo como plataforma para reflexão a respeito do papel do designer de Moda e como ele pode atuar e propor discussão/diálogo a partir do que cria. Neste sentido, entende-se a Moda como expressão cultural de identidade, passível de constante questionamento quanto à sua construção e inserção na sociedade, observando o contexto em que se insere como plural e em constante transformação. Assim, discutem-se padrões: de beleza, de produção, de uso e domínio técnicos, a partir do uso de peças já existentes, a recuperação de saberes artesanais, reaproveitamento e co-criação. Para o Projeto Pérola, o coletivo produz coleções que são desfiladas tendo por modelos as pacientes em tratamento ou remissão de câncer feminino (especialmente de mama, mas não só). Ao longo dos anos foram incorporados ao projeto voluntários dos cursos de Música, Dança e Beleza, além de pessoas que não pertencem aos quadros da Universidade ou do Hospital.

\section{O FREEFORM COMO METODOLOGIA}

Agora imagine chegar a Sanliurfa, desfazer a pequena mala, minha tímida proteção social e me surpreender: onde estão as minhas calças?

Eu estava em terra estrangeira, em meio a idiomas estranhos, costumes exóticos, num grupo formado por desconhecidos - só tinha aquela pequena mala para me proteger. $E$, naquele lugar, meu "dinheiro de plástico" não valia calças. (...)

\footnotetext{
${ }^{3}$ O CRSM Hospital Pérola Byington é um hospital da rede pública de saúde, vinculado ao Governo do Estado de São Paulo e localiza-se na região central da cidade de São Paulo. Presta assistência hospitalar na área ginecológica, destacando-se o tratamento do câncer ginecológico e mamário, a reprodução humana, planejamento familiar, esterilidade, sexualidade, violência sexual e uroginecologia. Além da atuação médico-hospitalar, promove educação em saúde da comunidade, pesquisa, ensino, desenvolvimento de tecnologia e intercâmbio com instituições de ensino, atendendo a região metropolitana da grande São Paulo.
} 
Rab. Nilton Bonder - Tirando Os Sapatos: o caminho de Abraão, um caminho para o outro

A fim de realizar as peças para o Projeto, voluntários, em sua maioria profissionais e estudantes de design de Moda, lançam-se ao exercício de aprender os trabalhos de agulha, a partir da promoção do diálogo entre os sujeitos a fim de proporcionar trocas em que aprendizado e ensino acontecem na mesma medida e repertórios são ampliados a partir do emaranhamento de experiências, construindo relações heterárquicas em que os autores assumem múltiplos papéis, como "facilitador, catalisador e incentivador, ao mesmo tempo aprendendo e ensinando" (FLETCHER; GROSE, 2011, p. 145).

Mesmo que a ideia seja a de produzir algo sem o uso de receita, a partir do imprevisível, vivenciando a experiência de fazer intensamente, faz-se necessário aprender os fundamentos. Ou seja, fazer o que propõe John Lewis (apud POYNOR, 2003, p. 12), designer e professor de Design Gráfico:

Antes de começar a romper as normas, é preciso saber quais elas são. Depois de conhecer os procedimentos adequados, pode-se analisar criticamente apar ver se, os desobedecendo deliberadamente, agrega-se algo ao método de comunicação ${ }^{4}$.

Assim, são organizados a cada edição, workshops que, de certa forma, lembram os círculos de aprendizado familiar, para que sejam aprendidos pontos e meios de fazer e também de desfazer. Opta-se por romper com a norma e experimentar o erro, buscar a forma livre sem pensar na peça final. De posse de partes produzidas parte-se para o busto, sem modelagem definida previamente.

Assim, a forma livre não reside apenas no procedimento, mas no processo como um todo e norteia o projeto, uma vez que as superfícies irregulares produzidas pelo coletivo também se prestam à discussão da irregularidade de modelos e a realidade dos padrões, sejam eles os padrões de corpo e beleza que serão vestidos por estas construções ou a ruptura acontecida nos projetos, planos e percepções de vida das pessoas contempladas no Projeto Pérola. Essas pessoas comuns, de vidas ordinárias, com seus planos, listas e receitas, (por que não?) vêem-se subitamente desviadas de suas rotas pela notícia de uma doença que também ela produz desordenadamente, células que fogem ao padrão.

Ou seja,

Cada fileira de significação se espraia em outra que contagia uma outra, de forma que um plano se reatualiza a partir da vibração de cada retomada, perfazendo uma cadeia ininterrupta de sentidos. (PRECIOSA, 2010, p. 48)

No ano de 2014, desejou-se incluir também pessoas não-designers que conhecessem as técnicas de crochê e tricô, muitas delas pacientes/modelos do

\footnotetext{
${ }^{4}$ Antes de empezar a quebrantar las normas uno há de saber cuáles son. Después de conocer los procedimientos adecuados se pueden analizar críticamente para ver si, desobedeciendólos deliberadamente, se añade algo al método de comunicación. (Tradução desta autora)
} 
Projeto. Desejava-se levar a elas a possibilidade de errar, desviar e trabalhar apenas tendo como parâmetros o material, as cores, a técnica e uma lista de medidas para a construção dos módulos que, unidos, dariam forma aos vestidos. Esperava-se que elas, tendo passado pela experiência do desvio, pudessem abraçar a metodologia e entendê-la melhor, envolvendo-se diretamente no processo. Tal tentativa foi frustrante. Aparentemente, conhecendo o modo tradicional de produção dos têxteis a fundo, as participantes não se deixaram derivar e desejar o erro, acabando por produzir partes que respeitavam as regras, figurativas como as muito conhecidas toalhinhas encontradas nas casas das mães e avós (Figura 8).

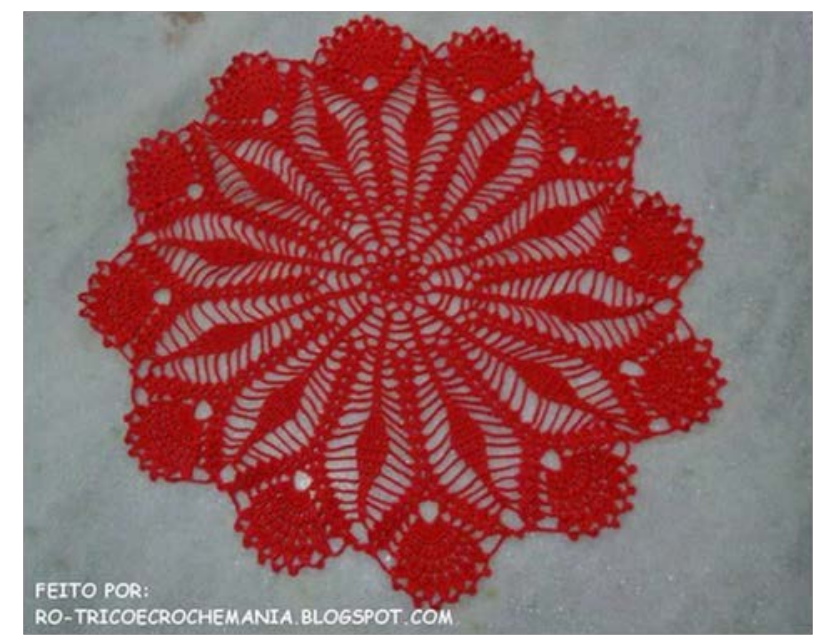

Figura 8: Toalha de crochê. (Fonte: www.tricoecrochemania.blogspot.com)

A partir de então, tomou-se a decisão de trabalhar apenas com os integrantes do coletivo. É possível que o designer seja mais resistente às abordagens de conhecidos leigos que insistentemente perguntam o que estão produzindo, ao encontrá-los tricotando, crochetando ou bordando sem receita, risco ou proposta aparente, e deseje a aventura de experimentar fazer diferente, um projeto sem forma definida, mas em que existe um ou mais propósitos. Talvez sejam eles os descritos por Preciosa (2010, p. 39):

Há os que se aventuram em produzir desvios. Coreografam marchas e contramarchas em sua passagem. Expandem seus campos de referência na medida em que exploram o túnel. Percebem que a reta orientação que possam tomar é sistematicamente sacudida por forças vivas que as faz entortar. Pelo corpo, uns arranhões necessários. Parecem poder arcar com a ruptura das formas estáveis.

Assim, desafiando a tradição, constrói-se uma coleção de desvios, em coletivo. Rompe-se a estrutura, parte-se a forma, delineiam-se novos modos de pensar o futuro. Desenham-se futuros possíveis, mas não previsíveis. Propõe-se uma coleção como quem pensa que:

Uma rede de roupas pode efetuar as conexões do amor através das fronteiras, da morte, porque a roupa é capaz de carregar o corpo ausente, a memória, a genealogia, bem como o valor material literal. (STALLYBRASS, 2008, p.26) 
Afinal, a atividade do designer de Moda compreende mais do que projetar "roupa", e mesmo projetar roupa é muito mais complexo do que a construção de um artefato que cumpre uma função objetiva e imediata - cobrir o corpo. É responsabilidade do designer de Moda não apenas a solução do problema "vestir", mas também oferecer ao usuário um mediador entre si e o mundo, aquilo que Hundertwasser denominará segunda pele (RESTANY, 2008). Essa segunda pele invariavelmente produz discursos, possibilitando aproximações ou afastamentos com o meio. A este coletivo e para este projeto, interessa a produção de segundas peles que, oriundas de diálogo e reflexão, produzem crítica sobre a própria indústria da Moda, em seus aspectos mais atrozes, como a sazonalidade, a produção maciça de itens de vestuário descartável e a promoção de padrões de beleza inatingíveis.

\section{CONSIDERAÇÕES FINAIS}

A produção de têxteis é historicamente anterior à produção de textos, porém, com ambos, produz-se discurso.

Ao romper a forma, também é possível, tanto no texto, quanto no têxtil, promover discussões que estão além do visível, do legível e do material e inventar novas possibilidades de construir existência e resistência, como proposto pelo Moda e Resiliência Coletivo de Design de Moda, a partir do produzido para o Projeto Pérola desde 2011.

\section{REFERÊNCIAS}

BONDER, Nilton. Tirando os Sapatos: o caminho de Abraão, um caminho para o outro. São Paulo: Editora Rocco, 2008.

DERDYK, Edith. Linha de Costura. São Paulo: Editora lluminuras, 1997.

FLETCHER, Kate GROSE, Lynda; (Org.). Moda \& Sustentabilidade, Design Para Mudança. São Paulo: Editora Senac, 2011.

GOSTELOW, Mary. Embroidery: traditional designs, techniques and patterns all over the world. Nova lorque: Arco Publishing, 1983.

POYNOR, Rick. No Más Normas: diseño gráfico posmoderno. México: Ediciones G. Gili, 2003

PRECIOSA, Rosane. Rumores Discretos da Subjetividade: sujeitos e escrituras em processo. Porto Alegre: Sulina: Editora da UFRGS, 2010.

RESTANY, Pierre. Hundertwasser: o pintor-rei das cinco peles - Editora Taschen, 2008.

STALLYBRASS, Peter. O Casaco de Marx: roupas, memória, dor. Belo Horizonte: Autêntica Editora, 2008. 